\title{
A CONVERSÃO DE ÁREAS ÚMIDAS EM USOS AGRÍCOLAS NA BACIA HIDROGRÁFICA DO BEIJA-FLOR - MG: ANÁLISE DO CARBONO TOTAL E IMPACTOS AMBIENTAIS EM MURUNDUS
}

\author{
Josimar dos Reis de Souza ${ }^{1}$
}

\begin{abstract}
Vania Silvia Rosolen ${ }^{2}$
RESUMO

Este trabalho propôs a análise da conversão de áreas úmidas em usos agrícolas no Cerrado, através do estudo da interferência dos fatores antrópicos em campos de murundus na Chapada UberabaUberlândia. Foi realizado o mapeamento do uso do solo da área escolhida, seguindo a metodologia de Rosa (2003), buscando identificar os impactos ambientais advindos da intensa utilização dos solos. Também foi realizada a coleta de amostras de solos, de acordo com as orientações da EMBRAPA (1997) e análise do carbono orgânico, buscando identificar alterações provenientes dos diferentes usos dos solos, como também, comparar com resultados obtidos anteriormente em outras pesquisas, ampliando a compreensão entre mudanças de uso do solo e dinâmica do carbono. Os resultados apontaram o intenso uso antrópico dos solos nas áreas de chapada sob vegetação original de Cerrado, que tem contribuído com a regressão das áreas úmidas, sobretudo, áreas de murundus, inclusive com a presença de drenos. As análises de carbono evidenciaram a importância das áreas de murundus para o estoque de carbono, constatando a forte de matéria orgânica no solo e elevado teor de carbono, sendo a preservação destas áreas de extrema importância para a manutenção dos estoques de carbono nos solos, contribuindo assim para a mitigação de gases de efeito estufa.
\end{abstract}

PALAVRAS-CHAVE: Murundus. Carbono Total. Impactos Ambientais.

\section{CONVERSION OF HUMID AREAS IN AGRICULTURAL USES IN BASIN OF BEIJA-FLOR - MG: ANALYSIS OF TOTAL CARBON AND ENVIRONMENTAL IMPACTS IN MOUNDS}

\begin{abstract}
This study proposes the analysis of the conversion of humid areas to agricultural uses in the Cerrado, by studying the interference of human factors in fields of mounds in Uberaba-Uberlandia Plateau. Mapping the land use of the chosen area was conducted following the methodology of Rose (2003),

\footnotetext{
1 Geógrafo, Mestrando em Geografia, Programa de Pós-Graduação em Geografia, Universidade Federal de Uberlândia (UFU). josimar.ig.geoufu@gmail.com.

${ }^{2}$ Doutora em Geociências, Professora no Departamento de Petrologia e Metalogenia, Universidade Estadual Paulista (UNESP), Campus Rio Claro. vrosolen@rc.unesp.br.
} 
seeking to identify the environmental impacts resulting from intense land use. Collecting soil samples was also performed, in accordance with the guidelines of EMBRAPA (1997) and the organic carbon analysis, seeking to identify changes from different land use, but also compare with results obtained previously in other studies, increasing the understanding between changes in land use and carbon dynamics. The results showed intense anthropogenic land use in the areas of plateau in original Cerrado vegetation, which has contributed to the decline of humid areas, especially areas of mounds, including the presence of drains. The carbon analyzes showed the importance of the areas of mounds for the carbon stock, noting the strong organic matter in the soil and high carbon content, and the preservation of these areas of importance to the maintenance of carbon stocks in soils, contributing so for the mitigation of greenhouse gases.

KEY-WORDS: Mounds. Total carbon. Environmental Impacts.

\section{LA CONVERSIÓN WET ÁREAS EN USOS AGRÍCOLAS EN LA CUENCA DEL BEIJA-FLOR - MG: ANÁLISIS DEL TOTAL DE CARBONO E IMPACTOS AMBIENTALES EN MONTÍCULOS}

\section{RESUMEN}

En este trabajo se propone la conversión del análisis de los humedales en el uso agrícola en el Cerrado, mediante el estudio de la interferencia de los factores humanos en los campos de montículos en Chapada-Uberaba Uberlandia. Hemos llevado a cabo el mapeo del uso del suelo de la zona elegida, siguiendo la metodología Rose (2003), tratando de identificar los impactos ambientales derivados de la utilización del suelo intensa. También promovimos la recogida de muestras de suelo, de acuerdo con las directrices de EMBRAPA (1997) y el análisis de carbono orgánico con el fin de identificar los cambios de diferentes usos de la tierra, así como para comparar con los resultados obtenidos previamente en otros estudios, la ampliación entendimiento entre los cambios de uso del suelo y la dinámica del carbono. Los resultados mostraron que el intenso uso del suelo antropogénico en las áreas de meseta bajo vegetación original del Cerrado, que ha contribuido a la regresión de los humedales, sobre todo, las áreas de montículos, incluyendo la presencia de drenajes. Análisis de carbono demostró la importancia de las áreas de montículos a las reservas de carbono, teniendo en cuenta la fuerte materia orgánica en el suelo y de alto contenido de carbono, y la preservación de estas áreas de extrema importancia para el mantenimiento de las reservas de carbono en los suelos, contribuyendo así que para la mitigación de gases de efecto invernadero.

PALABRAS-CLAVE: montículos. El carbono total. Los impactos ambientales.

\section{INTRODUÇÃO}

O desenvolvimento agrícola, ocorrido no Cerrado a partir da década de 1960, resultou em elevado grau de impactos ambientais. Estudos realizados por Sano et al. (2001) mostraram que em apenas quatro décadas mais da metade da paisagem natural do bioma Cerrado foi modificada. Henriques (2003) indicou que a taxa de expansão da atividade agropecuária sobre áreas de Cerrados foi de cerca de $3 \%$ ao 
ano, na década de 1990. As modificações ambientais geraram impactos relacionados ao desmatamento, à fragmentação dos habitats, à perda de biodiversidade, à erosão dos solos, à poluição dos copos d' água, ao uso intensivo de agroquímicos, à perda da capacidade produtiva de vários agroecossistemas, queimadas recorrentes, desequilíbrios nos estoques e nos fluxos de carbono e até mesmo a modificação climática em âmbito regional (KLINK; MACHADO, 2005).

O resultado do desmatamento acelerado é um mosaico de fitofisionomias remanescentes, que permanecem com quase todas as características próprias, mas são envolvidas por uma matriz alterada, condicionada a distúrbios antrópicos (EMBRAPA, 2008). Nas áreas de chapada dos Cerrados há a existência de fragmentos de áreas úmidas compostas pelas Veredas e Campos de Murundus, que continuam a sofrer alterações, seja pela drenagem das áreas para expansão da área agricultável, como também por contaminação dos solos proveniente do uso de agroquímicos e outros componentes para a correção dos solos.

Os Campos de Murundus se caracterizam como extensas áreas brejosas ou alagadiças com gramíneas, e presença de ilhas esparsas de Cerrado, nucleados por cupins. De maneira geral são denominados de microrrelevos. São importantes sob o ponto de vista da ecologia, pois apresentam indícios da evolução do gradiente vegetacional do Cerrado, nítidas relações entre a fauna e flora, estreita ligação com a perenização das nascentes e dos cursos d' água e interdependência com o regime climático (EMBRAPA, 1982). De maneira geral se apresentam com formas circulares com raio de rampa de até 10 metros e altura de 2 metros, nucleados por cupins, recobertos por vegetação lenhosa típica de Cerrado que contrasta com os campos limpos circundantes (EITEN, 1983).

A gênese dos murundus provém das teorias relacionadas a fatores bióticos e físicos. A primeira teoria associada à atividade de três espécies de térmitas, cada qual ligada à determinada fase de construção do microrrelevos, enquanto a segunda teoria atribui a origem dos murundus a processos do meio físico, no que diz respeito e erosão de antigas rampas coluviais seccionando a parte inferior das encostas durante o Holoceno, sendo os murundus relíquias de um paleorrelevo que remanescem nos 
sítios onde se instalaram os cupinzeiros. Também são considerados os processos de dinâmica superficial, especialmente a erosão (CASTRO JUNIOR, 2002).

Pelas características e contribuições dos campos de murundus, no que diz respeito a sua importância ecológica e reservatório hídrico, fica evidente a necessidade de sua conservação. Para isso torna-se necessário respeitar os limites naturais das áreas úmidas. Santos, Prantini e Oliveira (1990) afirmam que o estudo dos murundus adquire importância no sentido de estabelecer os limites ambientais do desenvolvimento econômico.

Outra característica particularmente importante que está relacionada à presença dos campos de murundus é o potencial que estas áreas têm de estocar carbono orgânico no solo. Considerando o conhecimento sobre a dinâmica da matéria orgânica do solo tropical, sabe-se que a temperatura e umidade elevadas contribuem para a elevação das taxas de decomposição da matéria orgânica. Elevadas taxas de decomposição são esperadas nos solos lateríticos bem drenados. A degradação e mineralização do carbono em ambientes tropicais são intensificadas pela umidade e temperatura elevadas, intensa atividade microbioana e a taxa de reposição é sustentada pela formação de serrapilheira (CERRI; CERRI, 2007). A alteração da umidade em presença de solo saturado reflete na diminuição da decomposição, à medida que aumentam as condições de ambiente anaeróbico. Contudo, se naturalmente há esta distinção em relação ao teor e, possivelmente, a natureza do carbono orgânico do solo, o uso agrícola e manejo do solo acentua estas distinções. Particularmente na chapada de Uberlândia-Uberaba, foco deste estudo, as mudanças nas propriedades e características dos solos relacionadas à conversão da vegetação natural são importantes, pois se trata de área de agricultura moderna consolidada.

Pela necessidade de entender melhor os impactos gerados pela agricultura nos campos de murundus devido à atividade agrícola, focando no possível empobrecimento do carbono orgânico do solo, o presente trabalho propõe o estudo da interferência dos fatores antrópicos em uma área de murundus na Chapada Uberaba-Uberlândia. Foi realizado o mapeamento do uso dos solos da área escolhida, buscando identificar os impactos ambientais advindos da intensa utilização 
dos solos. Também foi realizada a coleta de amostras de solos e análise do carbono total, buscando identificar alterações provenientes dos diferentes usos dos solos, como também, através de debate com resultados de outros autores, contribuir com outros estudos que têm sido realizados na área.

O quadrante escolhido para a realização do trabalho se encontra localizado na Microbacia do Ribeirão Beija-Flor e se configura como área representativa da paisagem regional, devido a intenso uso dos solos para fins agrícolas, que tem acarretado a regressão das áreas de Murundus. A bacia hidrográfica do Ribeirão Beija-Flor é importante para o abastecimento da área urbana do município de Uberlândia MG, além de ser enquadrada como nascente do Rio Uberabinha, um dos principais afluentes do Rio Araguari.

\section{PROCEDIMENTOS METODOLÓGICOS}

\section{Caracterização da Área de Estudo}

A Microbacia do Ribeirão Beija-Flor está localizada mesorregião do Triângulo Mineiro e Alto Paranaíba (Minas Gerais), entre a área Sul do Município de Uberlândia e Norte do município de Uberaba. As coordenadas limítrofes são de 1858'00" -

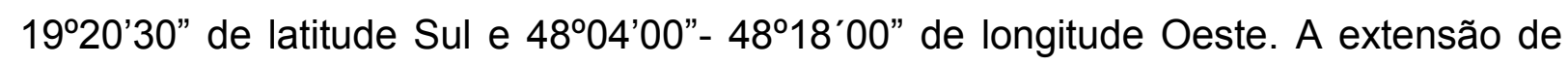
área drenada é de 398,54 km² $^{2}$ a distância da nascente/foz de 108,848 km. A bacia do Ribeirão Beija-Flor e o quadrante escolhido para análise dos murundus, são apresentados no mapa 1. A nascente do Ribeirão Beija-Flor está localizada próxima a rodovia BR-050, no município de Uberaba e sua foz se localiza nas proximidades da área urbana do município de Uberlândia, desaguando no Rio Uberabinha (BRITO, 2001). A sua importância no contexto regional se dá devido ao abastecimento público de Uberlândia, com cerca de 700.000 habitantes, uso para a irrigação, com extensas áreas de produção de soja, milho, cana-de-açúcar e pastagem. Além disso, a bacia da qual faz parte, do Rio Uberabinha, também é responsável por geração de energia elétrica. 
Mapa 1: Mapa de localização da bacia hidrográfica do Beija-Flor e área amostra

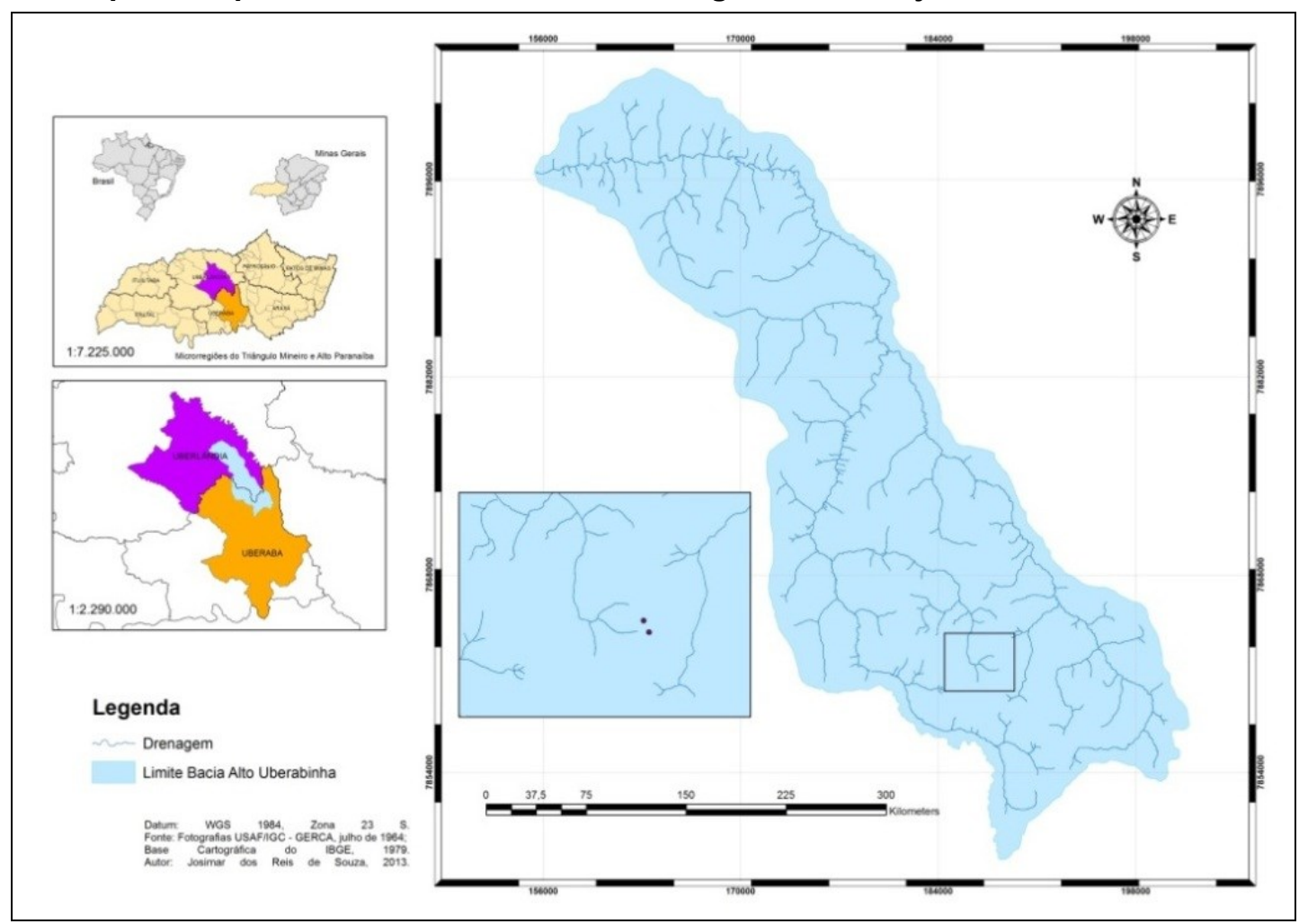

Fonte: IBGE, 2010. Autor: SOUZA, 2013.

O clima é tropical, com alternância de estações úmidas e secas, por influência sazonal de massas de ar. Os dois períodos bem definidos são: seco de abril a setembro e chuvoso de outubro a março. A pluviosidade varia de $800 \mathrm{~m}$ a $2.000 \mathrm{~mm}$, com média de $1.500 \mathrm{~mm} / \mathrm{ano}$ (. A temperatura média anual é de $22^{\circ} \mathrm{C}$. A geologia é representada pela Cobertura Detrítico-Laterítica Terciária e Quartenária, aluviões Holocênicos e Formação Marília assentados sobre os derrames basálticos da Formação Serra Geral provenientes de vulcanismo fissural em ambiente continental. A topografia é caracterizada por platôs com superfícies planas (chapadas). A vegetação original é o Cerrado, que foi quase todo substituído pela agricultura e pastagem. Os solos lateríticos prenominam, com argilas de baixa atividade, como caulinita, óxidos de ferro e de alumínio, baixo pH e teor de carbono, com exceção nos solos hidromórficos (ROSOLEN, et al., 2009). 


\section{Mapeamento do Uso do Solo}

O mapeamento do uso dos solos foi elaborado para o quadrante escolhido devido a sua representatividade na paisagem regional. O mapa foi elaborado seguindo as seguintes etapas: elaboração da Base Cartográfica na escala de 1:25.000, através da importação da folha topográfica digital (Córrego da Formiga articulação SE-22-Z-D-II-4-NO) elaborada pelo Exercito Brasileiro e publicadas pela Divisão de Serviço Geográfico - DSG (1983); geração da Carta-Imagem a partir da imagem RapidEye de 2012, disponibilizada pelo DMAE Uberlândia, com composição colorida Radideye3b4g5r; definição da chave de interpretação (quadro 1); classificação visual em tela, através do método de interpretação assistida; geração do Mapa de Uso dos Solos e o mapeamento das áreas de regressão de Murundus: a partir da resposta espectral dos níveis de umidade foi realizada a identificação de áreas que originalmente eram Campos de Murundus e passaram a ser utilizadas pela agricultura, sem perder sua característica de solos úmidos.

Quadro 1: Chave de Interpretação utilizada para o mapeamento do Uso dos Solos

\begin{tabular}{|c|c|c|c|}
\hline Tipo de Uso dos Solos & Descrição do Uso & $\begin{array}{c}\text { Padrões característicos de } \\
\text { interpretação }\end{array}$ & Exemplo \\
\hline Agricultura & $\begin{array}{l}\text { Áreas utilizadas com } \\
\text { culturas anuais ou } \\
\text { perenes em } 2012 .\end{array}$ & $\begin{array}{c}\text { Textura Lisa, Padrão } \\
\text { Geométrico, Tonalidade } \\
\text { verde escuro, verde claro. }\end{array}$ & \\
\hline Cobertura Vegetal Natural & $\begin{array}{l}\text { Áreas de cerrado ou Mata } \\
\text { Galeria em } 2012 .\end{array}$ & $\begin{array}{c}\text { Textura rugosa, Padrão Não- } \\
\text { Geométrico, Tonalidade } \\
\text { verde escuro. }\end{array}$ & \\
\hline Vereda & $\begin{array}{l}\text { Áreas úmidas com } \\
\text { características naturaisem } \\
2012 .\end{array}$ & $\begin{array}{l}\text { Textura lisa, Padrão Irregular, } \\
\text { Tonalidade verde médio, } \\
\text { verde escuro e cinza escuro. }\end{array}$ & \\
\hline Campos de Murundus & $\begin{array}{c}\text { Áreas úmidas com } \\
\text { características naturais em } \\
2012 .\end{array}$ & $\begin{array}{l}\text { Textura irregular, Padrão } \\
\text { irregular, Tonalidade verde } \\
\text { médio, verde escuro e cinza. }\end{array}$ & \\
\hline Regressão de Murundus & $\begin{array}{l}\text { Área naturalmente úmida } \\
\text { atualmente usada para a } \\
\text { agricultura em 2012. }\end{array}$ & $\begin{array}{c}\text { Textura Lisa, Padrão } \\
\text { Geométrico, Tonalidade } \\
\text { verde escuro, verde claro. }\end{array}$ & \\
\hline Áreas Construídas & $\begin{array}{l}\text { Área ocupada por } \\
\text { construções em } 2012 .\end{array}$ & $\begin{array}{l}\text { Textura rugosa, Padrão } \\
\text { regular, Tonalidade branco, } \\
\text { preto e cinza. }\end{array}$ & \\
\hline Drenos & $\begin{array}{c}\text { Área com drenos usados } \\
\text { para drenar áreas úmidas } \\
\text { em 2012. }\end{array}$ & $\begin{array}{l}\text { Textura rugosa, Padrão } \\
\text { regular, Tonalidade verde } \\
\text { escuro e cinza. }\end{array}$ & \\
\hline
\end{tabular}

Org.: SOUZA, 2013. 


\section{Análise do Carbono Total}

Bernoux (2002), afirma que o carbono orgânico do solo se concentra principalmente nos primeiros centímetros do solo, estando intimamente relacionado com a deposição de matéria orgânica superficial. Dessa forma a coleta das amostras de solos foi feita em três profundidades do solo: 0 - $10 \mathrm{~cm} ; 10-20 \mathrm{~cm} ; 30-50 \mathrm{~cm}$.

Foram escolhidos 2 pontos de amostragem (P1 e P2) em área de campos de murundus (P1 na base dos microrrelevos e P2 na parte alta dos microrrelevos). Essa escolha se deu em área amostral de relevância, com conflitos de uso dos solos inerente. Em cada profundidade foram coletadas três amostras para cálculo da média e desvio padrão. Assim no total foram 18 amostras de solos. As coletas foram feitas a partir da abertura de pequenas trincheiras feitas com o auxílio de um enxadão e as paredes foram limpas com faca comum, seguindo orientação dos manuais de coleta de amostras de solo (EMBRAPA, 1997).

O primeiro ponto - P1 (coordenada geográfica 19¹6,430'S e 4757,093'O) foi coletado na base do microrelevo e o segundo ponto - P2 (coordenada geográfica $19^{\circ} 16,432^{\prime} S$ e $47^{\circ} 57,087^{\prime} O$ ), foi coletado na parte alta do microrelevo. A figura 1 apresenta a disposição da coleta realizada.

Figura 1: Disposição da coleta de solos realizada

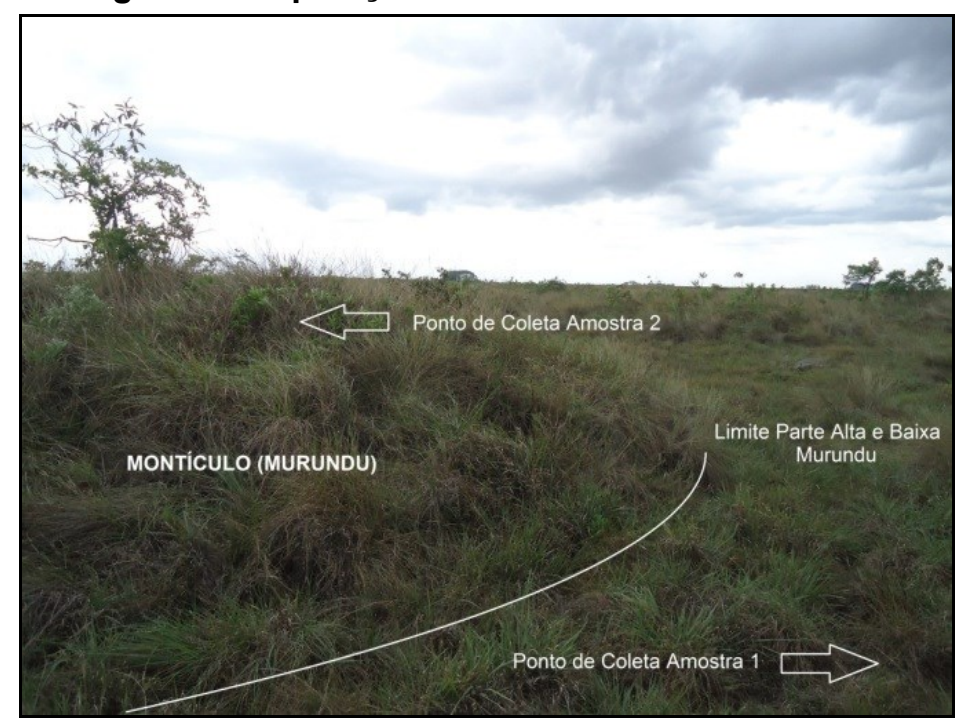

Autor: SOUZA, 2012. 
Após coletado, o material foi armazenado em saco plástico transparente e transportado ao Museu de Rochas e Minerais da Universidade Federal de Uberlândia, para secagem e posterior preparação para análise. Foi realizada a secagem em estufa a $50{ }^{\circ} \mathrm{C}$ e peneirada em peneira de malha com abertura de $0,210 \mathrm{~mm}$. Posteriormente foi pesada uma alíquota entre 4-5 gramas de solo referente a cada amostragem e analisado o teor de carbono orgânico total. Foi utilizado o equipamento TOC-VCSH com módulo para amostras sólidas SSM - 5000A da Shimadzu Corporation do Laboratório de Fotoquímica do Instituto de Química (LAFOT-UFU).

A concentração de carbono orgânico de cada amostra foi feita pela equação: Carbono Total $(\mathrm{CT})$ - Carbono Inorgânico $(\mathrm{Cl})=$ Carbono Total Orgânico (COT).

Para averiguação dos resultados, foram utilizados repetições de amostras enviadas ao Centro de Energia Nuclear na Agricultura (CENA), permitindo a verificação da exatidão da metodologia empregada, obtendo-se uma margem de erro de $0,3 \%$.

\section{RESULTADOS}

O mapeamento do uso do solo tem o objetivo de buscar o conhecimento das áreas de vegetação natural e também de utilização por parte do homem (ROSA, 2003), sendo importante devido à necessidade de compreender a organização do espaço, uma vez que o meio ambiente sofre transformações causadas pelos processos naturais e ações antrópicas. Para Assad e Sano (1998), o monitoramento da paisagem é primordial no planejamento, sendo o Sensoriamento Remoto de extrema importância no gerenciamento da paisagem.

Considerando as áreas com solos hidromórficos, se reconhece duas características que se distinguem principalmente pela presença ou ausência de palmácea buriti e dos microrelevos. Quando os buritis estão presentes estas áreas deprimidas e úmidas são chamadas de Veredas, enquanto que quando estão ausentes e comportam microrrelevos são chamados de Murundus. Na área de estudo, as veredas se constituem em prolongamento do eixo de drenagem. No 
segmento da drenagem com leito mais profundo, as veredas são substituídas pela vegetação ciliar. As áreas de murundus estão mais exteriorizadas em relação ao eixo de drenagem. Este posicionamento determina o maior impacto em relação à atividade antrópica, que ocorre e se amplia deste a década de 1960. A degradação dos murundus tem explicação histórica, pautada na direção do desenvolvimento do agronegócio brasileiro. Os avanços ocorridos na década de 1960 e seguintes, impulsionados pela interiorização do capital levaram a pecuária e à agricultura extensiva, com o arroz, soja, trigo e outros, deram início a uma acelerada e desordenada ocupação da região do Cerrado (IBAMA, 2003).

Estudos realizados por Schneider (1996) mostram que em 1964 na bacia do Beija-Flor havia $62,37 \%$ de áreas cobertas por Cerrado; 33,7\% por hidromorfia; 1,95\% de manchas esparsas de mata e apenas 1,98\% da área ocupada por ações antrópicas. Oliveira (2003) aponta que em 2009 na área de estudo havia 64\% de áreas utilizadas para agricultura, $20 \%$ de áreas úmidas, 12\% da área utilizada para silvicultura, 3,5\% de pastagem, somente 0,3\% de áreas remanescentes de Cerrado, $0,1 \%$ de áreas com presença de mineração e $0,1 \%$ de áreas de lagos artificiais. $A$ comparação dos resultados comprova o intenso processo de transformações ocorridos na bacia, fato que também está representado na área de estudo mapeada.

No mapa do uso dos solos do ano de 2012 (mapa 2), foram mapeadas oito categorias de uso: vegetação natural (fitofisionomias do Cerrado), veredas, murundus, agricultura, áreas construídas, área de regressão de murundus, drenos artificiais e drenagem superficial. 
Mapa 2: Uso dos Solos da área de estudo

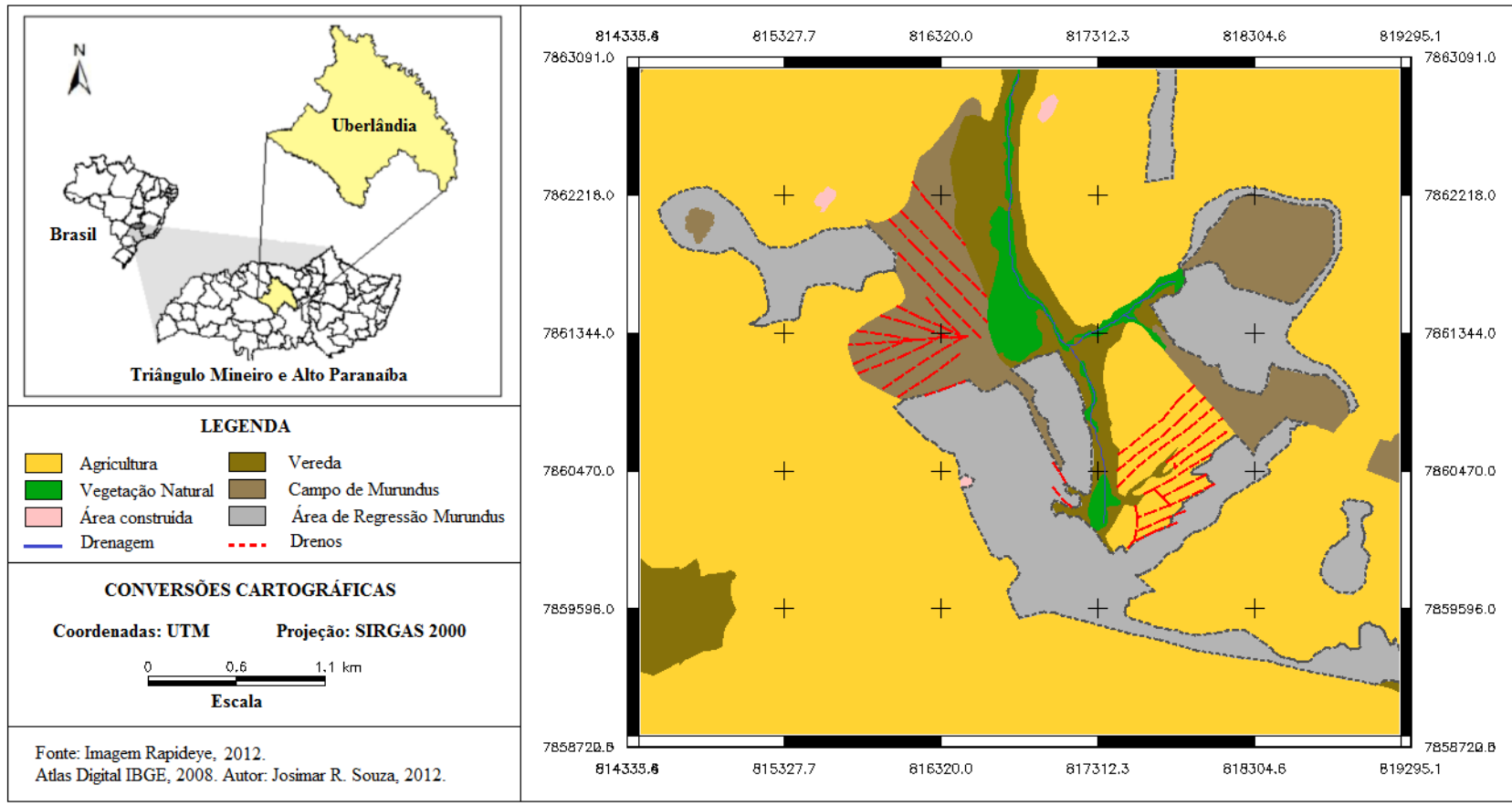

Autor: SOUZA, 2012.

Observa-se que, na área mapeada, grande parte das áreas estão ocupadas com agricultura que, historicamente, substituíram áreas a vegetação natural do Cerrado. São nítidas e relevantes as informações obtidas no mapa do uso dos solos. A predominância absoluta da agricultura (cor laranja) em grande escala, que transformou a paisagem em extensas áreas voltadas para a produção agroexportadora, expande a agricultura para além das áreas com solos bem drenados e avançam nos solos originalmente mal drenados, constituindo áreas que houve a regressão de murundus (cor cinza), que apesar de manter características hidromórficas no solo, já são consolidadas como áreas de produção de grãos. As áreas remanescentes de Murundus (cor marrom claro) se configuram como fronteiras para a expansão agropecuária, com limites regulares e fragmentados.

Na bacia hidrográfica, ainda é comum encontrar a existência de drenos (linha vermelha), uma vez que as raízes dos cultivos agrícolas não suportam condições anaeróbicas. A drenagem destas áreas úmidas possibilita a ampliação das áreas agricultáveis. Os drenos promovem o escoamento de toda a água do lençol, direcionando-as inteiramente aos canais fluviais em poucas horas após cessar o 
episódio de chuva. Se por um lado essa intervenção no meio favorece agricultura em solos naturalmente impróprios, por outro lado, esvazia um extenso corpo d'água que pode abastecer as nascentes e cursos d'água durante os seis meses secos, atribuindo-lhes perenidade. As consequências dessas interferências sobre o meio natural são ainda desconhecidas em sua totalidade, mas seguramente trazem negativos impactos para o meio físico, biológico e para a garantia de disponibilidade hídrica.

As veredas (marrom escuro) também apresentam áreas de regressão, com presença de drenos e comumente na área, são represadas e utilizadas para extração de minerais. Por se tratarem de espaços protegidos por lei, se configuram como recarga do lençol freático. A drenagem desses solos, como intervenções antrópicas em seu curso natural, acaba por trazer problemas de encrostamento e endurecimento dos solos, perda de matéria orgânica e aumento da presença de ácidos (CASTRO JUNIOR, 2002).

O solo de áreas úmidas se constitui importante armazenador de carbono, o que garante o equilíbrio do ecossistema. Também, o carbono no solo tem importante papel no balanceamento dos gases do efeito estufa, através do denominado sequestro de carbono. O relatório do IPCC (2007) afirma que o sequestro de carbono pelos solos se trata do mecanismo com maior potencial para a mitigação dos gases do efeito estufa, com uma contribuição estimada em $89 \%$, sendo que entre as ações governamentais para mitigação das emissões dos gases de efeito estufa devem permear o modelo de utilização dos solos para a agropecuária. Nesse sentido o Carbono assume papel de destaque na campanha de mitigação da emissão de gases de efeito estufa. Nesse sentido, analisar as possíveis alterações no teor de carbono dos solos provenientes dos usos entrópicos, poderá contribuir para a busca da conservação destes ecossistemas.

Nos últimos anos alguns estudos envolvendo Carbono têm sido realizados no âmbito da Chapada do Oeste Mineiro, mais especificamente, nas áreas de nascentes do Rio Uberabinha. Estes têm buscado identificar a relação do uso e manejo dos solos com a agregação e emissão de Carbono. Também visaram à análise do 
Carbono em áreas úmidas, buscando aprofundar o estudo dessas áreas com dinâmica complexa.

Estudos realizados por Rosendo (2010), utilizando as análises de teor do Carbono na Bacia Hidrográfica do Rio Araguari, na qual a bacia do Uberabinha faz parte, mostraram que a agricultura e pecuária possuem elevado potencial para estocar Carbono no solo. Os resultados apontaram que o manejo adequado das áreas agrícolas permite o aumento do estoque de carbono do solo. Também identificaram através de mapeamento que $80 \%$ das áreas de pastagens cultivadas apresentam algum grau de degradação, merecendo especial atenção, para sua recuperação.

Resende (2011) buscou identificar as relações da conversão do uso dos solos e o potencial de estoque do Carbono na bacia do Ribeirão Bom Jardim, afluente do Rio Uberabinha. A pesquisa buscou verificar o teor e origem do carbono orgânico do solo, em áreas de conversão da vegetação de Cerrado em áreas de cultivo de soja, rotação com milho, e de pastagens manejadas e degradadas. Através da análise do carbono total $(\mathrm{C} \%)$ e do carbono isotópico $\left(\delta^{13} \mathrm{C}\right)$, de quatro categorias representativas de uso, apontaram que a mudança ocorrida no uso dos solos provocou mudanças importantes no teor e natureza do carbono do solo.

Em relação aos estudos realizados em áreas úmidas da bacia estudada, Machado (2011), buscou analisar o teor do Carbono Orgânico em áreas de vereda na bacia do Beija-Flor. O estudo em topossequência determinou que o teor de Carbono possui distribuição regular, variando de forma constante durante o perfil topográfico, estando de acordo com a lógica da altura topográfica e distanciamento do lençol freático.

Os estudos realizados na área, pelos autores apresentados, abarcaram análise do Carbono em diferentes usos dos solos, como também em áreas de Cerrado arbóreo e em áreas de Vereda. Nesse sentido, buscou-se a realização de análise do carbono total em área com características de campos de murundus, para possibilitar uma breve discussão sobre o teor de carbono nesse tipo de hidromorfia e compará-lo com os resultados apresentados pelos autores. 
A tabela 1 apresenta o resultado do Carbono total para as amostras colhidas na área de Murundus. Os resultados encontrados das análises de Carbono Orgânico Total (COT) foram de $2,4957 \%$ no ponto 1 e $2,6360 \%$ no ponto 2 . O resultado foi calculado a partir da média entre o Carbono Total (SSM-TC), o Carbono Inorgânico (SSM - IC) e o Carbono Orgânico (SSM - TOC).

Tabela 1: Resultado de Carbono Total das amostras de solo coletadas em área

\begin{tabular}{cc|c|c|c} 
Solo/Carbono Total & SSM/TC (\%) & \multicolumn{1}{c}{ SSM/IC (\%) } & SSM/TOC (\%) & Média (\%) \\
\hline \multirow{3}{*}{ Amostra Ponto 1 } & 0,0251 & 0,1103 & 2,4000 & \\
& 2,4700 & 0,0921 & 2,3780 & 2,4957 \\
& 2,8240 & 0,1145 & 2,7090 & \\
\hline \multirow{2}{*}{ Amostra Ponto 2 } & 2,8490 & 0,0496 & 2,8000 & \\
& 2,6070 & 0,0586 & 2,5480 & 2,6360 \\
& 2,6950 & 0,1358 & 2,5600 & \\
\hline
\end{tabular}

Org.: SOUZA, 2013.

Os resultados apontam uma pequena variação entre os teores de carbono na base (ponto 1) e na parte alta (ponto 2) do microrelevo, sendo o teor deste último, mais elevado que o do primeiro. Uma das características dos Murundus é a atividade das térmitas, que fazem com que solos mais profundos sejam transportados para as partes mais altas. Dessa forma solos da subsuperfície desta área úmida, por estarem em contato direto com o lençol freático todo o período do ano, apresentam maiores teores de carbono, conforme estudos de Machado (2011) mencionados anteriormente.

A atividade das terminas transportam solos para as partes mais altas do microrelevo, podendo ser um dos fatores determinante para que os teores encontrados nas partes altas do microrelevo sejam maiores que das partes baixas, com presença de água apenas parte do ano. Estudos realizados por Rodrigues (2002) em campos de Murundus no interior do Mato Grosso, reforçam esta hipótese. O trabalho afirmar que as térmitas durante a construção de seu habitat transportam agregados de profundidades superiores a $60 \mathrm{~cm}$, trazendo solos de áreas em que estes permanecem imersos na água do lençol freático durante todo o ano. Egler (1984) observou que as térmitas concentram a atividade de construção dos ninhos no início e no final da estação chuvosa, transportando 8,5 toneladas por ha/ano de solo, aumentando seus termiteiro sem cerca de $40-70 \%$ do volume. Nesse sentido, é 
possível perceber a contribuição da bioarquitetura das térmitas no processo de transportes do solo.

Outra questão que merece destaque é a dinâmica da água em campos de Murundus, com comportamento peculiar. Este é devido ao regime pluviométrico, mantendo-se saturados ou supersaturados em água nos meses chuvosos e esvaziando-se lenta e continuamente nos meses secos, por meio do rebaixamento do nível freático. Nos estudos realizados por Castro Junior (2002) foi identificada a presença de dois lençóis freáticos, sendo um suspenso de características sazonais e outro perene e profundo, separado do anterior por camada argilosa confinante. Esta peculiaridade pode ser o fator determinante para as diferenças apresentadas entre as porcentagens de carbono total encontrados em áreas de Murundus, com as porcentagens encontradas em Veredas nos estudos de Machado (2011).

Também característica dos microrelevos é a existência de espécies de Cerrado de porte arbustivo. Estas podem contribuir em um maior volume de serrapilheira e por consequência em uma maior quantidade de Matéria Orgânica no solo, como nas apresentadas na parte alta (ponto 2) do microrelevo analisado, elevando assim as taxas de Carbono.

Nota-se que os teores de Carbono encontrados neste estudo em campos de Murundus, como também nas análises realizadas por Machado (2011), são significativamente maiores que os teores de Carbono em áreas de Cerrado arbóreo, analisados por Resende (2011). Pode-se afirmar que esta diferença se dá primordialmente pela presença de água e matéria orgânica pouco humificada. Tal fator demonstra a importância das áreas úmidas como áreas que estocam Carbono. Estas áreas necessitam de total atenção dos órgãos ambientais, pois devem ser preservadas, possibilitando assim a proteção de ecossistemas importantes pela sua fauna-flora, por se constituírem áreas de nascentes e importantes mananciais de água e por se caracterizarem como áreas armazenadoras de Carbono, e, portanto importantes para o alcance dos objetivos de diminuição das emissões de Carbono. 


\section{CONCLUSÃO}

Os estudos ambientais tem importante papel diante das rápidas mudanças e intensificação dos processos do mundo contemporâneo. Nesse sentido, o mérito dos estudos ambientais realizados merece destaque. O Cerrado sempre foi visto como área secundária para a preservação, fato comprovado pela realidade apresentada neste estudo, em que economicamente este bioma é primeiramente lembrado como área de produção de grãos, de pecuária extensiva e se esquece das riquezas da fauna, flora e outros recursos naturais. Cabe às instituições de pesquisa que fazem parte desse bioma, demonstrar através de pesquisa os prejuízos e ganhos causados pela intensa utilização dos seus recursos naturais.

O estudo das áreas úmidas é fundamental para se entender as dinâmicas das bacias hidrográficas. Não é possível se pensar em dinâmica hídrica, sem levar em consideração as dinâmicas do lençol freático. Nesse sentido, este trabalho buscou contribuir para o melhor entendimento destas áreas. O estudo do carbono como indicador de qualidade e/ou degradação dos solos se mostrou eficaz no entendimento da relação das áreas úmidas com estoques de carbono. Esses estudos merecem atenção e financiamento das agências e órgãos de fomento, por se tratarem de pesquisas ligadas diretamente às questões recentes de diminuição de emissões de gases de efeito estufa.

\section{REFERÊNCIAS}

BERNOUX, M.; CARVALHO, M. C. S.; VOLKOFF, B.; CERRI, C. C. Brazil's soil carbon stocks. In: Soil Science Society American Journal, v. 66, 2002. p.88-896.

BRITO, J. L. S. Adequação das potencialidades do uso da terra na Bacia do ribeirão Bom Jardim no Triângulo Mineiro (MG): Ensaio de Geoprocessamento. (Tese de Doutorado) - Faculdade de Filosofia, Letras e Ciências Humanas, Universidade de São Paulo. São Paulo: USP, 2001.

CASTRO JÚNIOR, P. R. Dinâmica da Água em Campos de Murundus do Planalto dos Parecis. (Tese de Doutorado) - Faculdade de Filosofia, Letras e Ciências Humanas, Universidade de São Paulo. São Paulo: USP, 2002. 
CERRI, C. C.; CERRI, C. E. P. Agricultura e aquecimento global. In: Boletim da Sociedade Brasileira de Ciência do Solo, 32, 2007. p. 40-44.

EITEN, G. Classificação da vegetação do Brasil. Brasília: Conselho Nacional do Desenvolvimento Científico e Tecnológico, 1983.

EMBRAPA. Levantamento de média intensidade de solos e avaliação da aptidão agrícola das terras do Triângulo Mineiro. Rio de Janeiro: EMBRAPA, 1982.

Manual de métodos de análise de solo. 2. ed. Rio de Janeiro,1997.

Cerrados Ecologia e Flora - Volume 1. Brasília: Embrapa Informação Tecnológica, 2008.

HENRIQUES, R. P. B. O futuro ameaça. Ciência Hoje. Rio de Janeiro, v. 33, n. 195, 2003.

IBAMA. ECOSSISTEMAS BRASILEIROS: Projetos de Conservação e Manejo de Ecossistemas, 2003. Disponível em: <http://www.ibama.gov.br/ecossistemas/cerrado.htm. >. Acesso em: Março de 2012.

IPCC. Land use change, and forestry: Special report of the IPCC. Cambridge: Cambridge University Press, 2000. 347 p.

KLINK, C. A.; MACHADO, R. B. Conservation of the brazilian Cerrado. In: Conservation Biology, n. 19, 2005.

MACHADO, H. A. Análise do teor de carbono orgânico em uma Vereda do córrego Beija-Flor, Uberlândia-MG. (Monografia) - IG, Universidade Federal de Uberlândia, 2011, 51 f.

OLIVEIRA, D. A. As áreas de preservação permanente em topo de chapada e a adequação à legislação. (Dissertação de Mestrado) - IG, Universidade Federal de Uberlândia, 2013. 114 f.

RESENDE, T. M. Conversão de uso e potencial de estoque do carbono nos diferentes usos do solo e cobertura vegetal na Bacia do Ribeirão Bom Jardim no Triângulo Mineiro (MG). (Dissertação de Mestrado) - IG, Universidade Federal de Uberlândia, 2011, 142 f.

ROSA, R. Introdução ao sensoriamento remoto. $5^{\text {a }}$ ed. Uberlândia: Edufu, 2003.

ROSENDO, J. Estoque de Carbono nos solos da Bacia do Rio Araguari - MG: estimativas, modelagem e Cenários. (Tese de Doutorado) - IG, Universidade Federal de Uberlândia, 2010. 312 f.

ROSOLEN, V; et al. Qualidade dos sedimentos no rio Uberabinha (Uberlândia, MG) e implicações ambientais. In: Revista Brasileira de Geociências, v. 39, n 1, 2009.

SANO, E. E.; JESUS, E. T.; BEZERRA, H. S. Uso de um sistema de informação geográfica para quantificação de áreas remanescentes do Cerrado. Planaltina, DF: Embrapa Cerrados, 2001.

SANTOS, A. R.; PRANTINI, F. L.; OLIVEIRA, A. M. S. Limites ambientais do desenvolvimento: geociências aplicadas, uma abordagem tecnológica da biosfera. ABGE, artigo técnico, $20 \mathrm{p}$.

SCHNEIDER, M. O. Bacia do Rio Uberabinha: Uso agrícola do solo e meio ambiente. (Tese de doutorado), Instituto de Geociências, Universidade de São Paulo, São Paulo, 1996. 157 f. 